\title{
The Effect of Hydraulic Characteristics of Volcanic Materials on Yield of Roses Grown in Soilless Culture
}

\author{
M. Raviv ${ }^{1}$ \\ Department of Ornamental Horticulture, Agricultural Research Organization, Newe Ya'ar Research \\ Center, P.O. Box 1021, Ramat Yishay 30095, Israel \\ R. Wallach \\ The Seagram Center for Soil and Water Sciences, Faculty of Agricultural Food and Environmental \\ Sciences, The Hebrew University of Jerusalem, P.O. Box 12, Rehovot 76100, Israel
}

\author{
A. Silber, ${ }^{2}$ Sh. Medina, and A. Krasnovsky \\ Department of Ornamental Horticulture, Agricultural Research Organization, Newe Ya'ar Research \\ Center, P.O. Box 1021, Ramat Yishay 30095, Israel
}

\begin{abstract}
Rose (Rosa sp.) plants ('Mercedes') were grown in yellow tuff (YT) (volcanic ash, scoria) and pumice from Italy (PI) and Greece (PG) for which physical and hydraulic characteristics were determined. The differences among the measured retention curves of these materials result in significant differences among their relative hydraulic conductivity functions. The hydraulic conductivity of YT is much higher than that of PI, which is higher than that of PG. The plants were subjected to optimal growth and nutrition conditions. Irrigation was controlled using electronic tensiometers, at suction values well within the range of easily available water: $13 \mathrm{~cm}$ for $Y T$ and $8 \mathrm{~cm}$ for the two pumice types. Nonetheless, yields were significantly higher in YT than in PI; yields were even lower in PG. We suggest that the limiting factor was the dynamic water availability to the plants, which is affected mainly by the unsaturated hydraulic conductivity. The relative hydraulic conductivity of YT at $13 \mathrm{~cm}$ is more than an order of magnitude higher than that of PI at $8 \mathrm{~cm}$. The relative hydraulic conductivity of PG at 8 $\mathrm{cm}$ is two orders of magnitude lower than that of YT at $13 \mathrm{~cm}$. It seems that the current concept of easily available water, based on a predetermined suction range, independent of the hydraulic characteristics of the media, is not an appropriate parameter for irrigation management in soilless culture. The unsaturated hydraulic conductivity, being a characteristic function of the medium and highly sensitive to moisture variation, indicates better the actual availability of water to the roots. Therefore, it should be used for irrigation control in containers filled with porous substrates.
\end{abstract}

The simultaneous and continuous supply of easily available water (EAW) and oxygen to the whole plant root system is an essential prerequisite for optimal production of plant material. In well-aerated soilless media, oxygen is usually in adequate supply even under conditions of continuous or very frequent irrigation. Matching water flow from irrigation emitters - through the root medium to the plant-with the transpirational demand, is necessary to enable high stomatal conductance. This, in turn, enables uninterrupted $\mathrm{CO}_{2}$ fixation, efficient transpirational cooling of the plant canopy and translocation of ions (including essential nutrients) and organic molecules into, within and out of the living plant, driven by the transpirational stream.

As media differ in their physical characteristics, optimal irrigation scheduling should be formulated specifically for each medium type. Such scheduling should enable water flow from the medium to the roots, synchronously with the transpirational demand, as determined by the climatic conditions, i.e., solar radiation, vapor pressure deficit and air velocity, and plant variables such as leaf area and stomatal conductance.

Quantification of the hydraulic processes that take place within the container during and between irrigations is essential for the

Received for publication 4 May 1998. Accepted for publication 13 Nov. 1998. Agricultural Research Organization contribution 207/98. We express our gratitude to Tuff Merom Golan for a grant to M.R. that financed in part this research. The cost of publishing this paper was defrayed in part by the payment of page charges. Under postal regulations, this paper therefore must be hereby marked advertisement solely to indicate this fact.

${ }^{1}$ To whom reprint requests should be addressed; fax, 972-4-9836936; e-mail, vfnraviv@volcani.agri.gov.il.

${ }^{2}$ Current address: Institute of Soils and Water, Agricultural Research Organization, The Volcani Center, P.O. Box 6, Bet Dagan 50250, Israel. effective management of irrigation and fertilization. This is especially important in container media in which low water buffering capacity (WBC) may result in a rapid decrease in the water content $(\theta)$ and, consequently, in unsaturated hydraulic conductivity $(\mathrm{K})$, with increasing suction (Wallach et al., 1992 a, 1992b).

Water and nutrient availability to plants depends on the actual moisture flux from the medium to the plant roots rather than on the water volume in the container. This flux is affected mainly by the momentary value of the hydraulic conductivity. Therefore, knowledge of its variation with water suction, $\mathrm{K}(\mathrm{h})$, or water content, $K(\theta)$, is of vital importance for effective management of irrigation that provides the needed water amounts for optimal plant water use. However, the hydraulic characterization of container medium for irrigation management has been based almost exclusively on the retention curve, $\theta(\mathrm{h})$, and on the hydraulic conductivity of the saturated medium, $\mathrm{K}_{\mathrm{s}}$. Recently, $\mathrm{K}(\mathrm{h})$ was measured for tuff (Wallach et al., 1992a) and for composted grape marc and its mixture with tuff (Wallach et al., 1992b). Analyzing these data reveals that significant changes in $\mathrm{K}(\mathrm{h})$, water and solute fluxes to the roots are expected between irrigations even if the moisture content is maintained within the range that is defined in the literature as EAW (10 to $50 \mathrm{~cm}$ ).

In the present work we attempted a first approximation toward the approach of estimating the effect of $K(h)$ on water availability and yield by using three types of volcanic materials, having a wide range of physical characteristics. Pumice is a porous volcanic material that was suggested as a substitute for perlite in container media (Noland et al., 1992) and for rockwool as a stand-alone substrate (Gunnlaugsson and Adalsteinsson, 1995). However, the latter work showed that the content of EAW in pumice is very low 
in spite of its relatively low bulk density (BD), and they thus warn of the need for a permanent water reservoir in the medium, to prevent water stress. Tuff (scoria) is widely used in Israel and elsewhere in the world as a growth medium for roses and other ornamental and vegetable crops and as a component in substrates for pot plants. Mineralogical and chemical characteristics of various tuff types were described by Silber et al. (1994). Pumice from Lipary, Italy (PI) and Greece (PG) and one type of yellow tuff (YT) from the Golan Heights, Israel, were tested under predetermined irrigation and nutrition conditions, planned to suit the individual properties of each of the media.

\section{Materials and Methods}

Cultural conditions and experimental design. 'Mercedes rose plants, grafted on a clonal Rosa indica L. rootstock (Gilad, Israel) were planted in March 1992 in 10-L buckets filled with one of the three media: YT, PI, and PG. Eighteen plants were placed on $1 \times 3 \mathrm{~m}$. bed. Five beds were used as replications per medium in a randomized block design.

Plant pinching, climate control and plant protection procedures were carried out according to commercial recommendations. Flowers were harvested during 2 years: from October 1992 until the end of September 1994, 6 d a week. All flowers shorter than $30 \mathrm{~cm}$ were discarded; the remaining flowers were counted, graded according to length and weighed. Flowers shorter than $35 \mathrm{~cm}$ were considered not marketable. The remaining flowers were sorted according to commercial quality: only top quality flowers were considered marketable. All results were subjected to analysis of variance and Duncan's multiple range test. The experiment was terminated on 2 Oct. 1994.

Differential fertilization regimes were formulated in order to achieve similar nutrient availability in the three media. Chemical analysis of irrigation and drainage water was conducted every 2 weeks to verify that this goal was being achieved.

Irrigation was initiated independently by determining specific threshold suctions for each media. The suction threshold levels were determined according to Raviv et al. (1992, 1993). The effect of various water suctions on plant parameters (stomatal conductance and net photosynthesis) was measured before starting the main experiment using five High Flow tensiometers (Hydratal 90, A. Tal, Israel) that were installed in each medium at a depth of 10 $\mathrm{cm}$. As a result of these preliminary estimates, irrigation pulses were actuated whenever water suction reached values of 13,8 , and $8 \mathrm{~cm}$ for YT and the two pumice types, respectively. Electronic High Flow tensiometers (A. Tal, Israel) were located at a depth of $10 \mathrm{~cm}$ and connected to the irrigation computer via dry on-off connectors. A period of 1 to 2 weeks is required to obtain a full contact between the medium and the tensiometer. Tensiometer readings were not recorded over time. However, periodic observations were conducted to ensure equal readings of the electronic and

Table 1. Average number of irrigation pulses per day, average amount of irrigation water (IRR) per plant and evapotranspiration (ET), leaching fraction (LF), and electrical conductivity (EC) of the leachate for the three media studied [yellow tuff (YT) and pumice from Italy (PI) and Greece (PG)] from August 1993 to September 1994.

\begin{tabular}{lccccc}
\hline \hline Medium & $\begin{array}{c}\text { Pulses/ } \\
\mathrm{d}\end{array}$ & $\begin{array}{c}\text { IRR } \\
(\mathrm{L} / \mathrm{d})\end{array}$ & $\begin{array}{c}\text { LF } \\
(\%)\end{array}$ & $\begin{array}{c}\text { ET } \\
(\mathrm{L} / \mathrm{d})\end{array}$ & $\begin{array}{c}\mathrm{EC} \\
\left(\mathrm{dS} \cdot \mathrm{m}^{-1}\right)\end{array}$ \\
\hline YT & 7 & 1.80 & 41 & 1.06 & 3.47 \\
PI & 15 & 1.89 & 45 & 1.04 & 3.23 \\
PG & 17 & 1.62 & 46 & 0.87 & 3.21 \\
\hline
\end{tabular}

regular tensiometers. The manufacturer calibrated both tensiometer types as found necessary. The amount of water per irrigation pulse was calculated according to the retention curves, so that water added in each pulse will generate a desired leaching fraction (LF) upon returning to the set point levels. Leaching fractions were selected to maintain leachate's electrical conductivity (EC) of $3.0<\mathrm{EC}<3.5 \mathrm{dS} \cdot \mathrm{m}^{-1}$. Drainage water was collected from two buckets per bed and both LF and EC were measured three times a week. Representative number of irrigation pulses and amount of applied and evapotranspired water per day from August 1993 to September 1994 are presented in Table 1.

Physical Characteristics of The media. The following physical characteristics of the media were determined: particle size distribution (PSD), BD, and water retention curve for a suction range of 0 to $100 \mathrm{~cm}$. The physical definitions are those suggested by Bunt (1988). Effective pore space (EPS): volumetric total pore space that can be actually filled with water. Air-filled porosity (AFP): volumetric content filled with air at $10 \mathrm{~cm}$ water suction. EAW: volumetric content of water held at 10 to $50 \mathrm{~cm}$ water suction. WBC: volumetric content of water held at 50 to $100 \mathrm{~cm}$ water suction. The water retention curve and the BD were determined by the hanging-column method (Raviv and Medina, 1997). Four samples were measured in all the analyses above. Only minute differences were found among samples of the same medium and the results presented are the average of these samples.

Hydraulic PROPERTIES. The retention characteristic model proposed by van Genuchten (1980) is used to fit the measured retention curves and to describe the hydraulic properties of the YT and the two pumice types. This model is expressed by the following equation

$\mathrm{S}_{\mathrm{e}}=\left[1+(\alpha \mathrm{h})^{\mathrm{n}}\right]^{-\mathrm{m}}$

where $\mathrm{h}$ is the water suction (cm of water) and $\mathrm{S}_{\mathrm{e}}$ is the effective saturation, $S_{\mathrm{e}}=\left(\theta-\theta_{\mathrm{r}}\right) /\left(\theta_{\mathrm{s}}-\theta_{\mathrm{r}}\right)$, where the subscripts $\mathrm{s}$ and $\mathrm{r}$ refer to the saturated and residual values of $\theta$, respectively. The parameters $\alpha, m$, and $\mathrm{n}$ are empirical and determined by a best-fit procedure. This model describes well the measured retention curves for different container media (Wallach et al., 1992a, 1992b; da Silva et al., 1993). The main advantage of Eq. (1) is the possibility to combine it with a predictive model for the unsaturated hydraulic conductivity, thus forming the basis for a combined hydraulic model. Substituting Eq. [1] into the model developed by Mualem (1976) for the relative hydraulic conductivity and assuming $\mathrm{m}=1-1 / \mathrm{n}$, leads to (van Genuchten, 1980)

$\mathrm{K}_{\mathrm{r}}(\mathrm{h})=\frac{\left[1-(\alpha \mathrm{h})^{\mathrm{n}-1}\left[1+(\alpha \mathrm{h})^{\mathrm{n}}\right]^{-\mathrm{m}}\right]^{2}}{\left[1+(\alpha \mathrm{h})^{\mathrm{n}}\right]^{\mathrm{m} / 2}}$

Wallach et al. (1992a, b) and da Silva et al. (1993) applied this model and determined $\mathrm{K}(\mathrm{h})$ curves for several container media. The predicted $\mathrm{K}(\mathrm{h})$ curves agreed well with measured hydraulic conductivities for the substances examined in those studies.

\section{Results}

Physical characteristics of the media. Analysis of PSD revealed large variation among media (Fig. 1). Compared with the two pumice types, YT contains a higher proportion of fine particles. Porosity characteristics cannot be explained simply by the differences in PSD (Table 2), suggesting that a fraction of the total porosity is ineffective due to the existence of closed or hard-to-wet pores (Bunt, 1988; Teres et al., 1997). Figure 2 suggests that although EPS of the media is of the same order of magnitude, most of the pores of the two pumice types and to some extent also those 

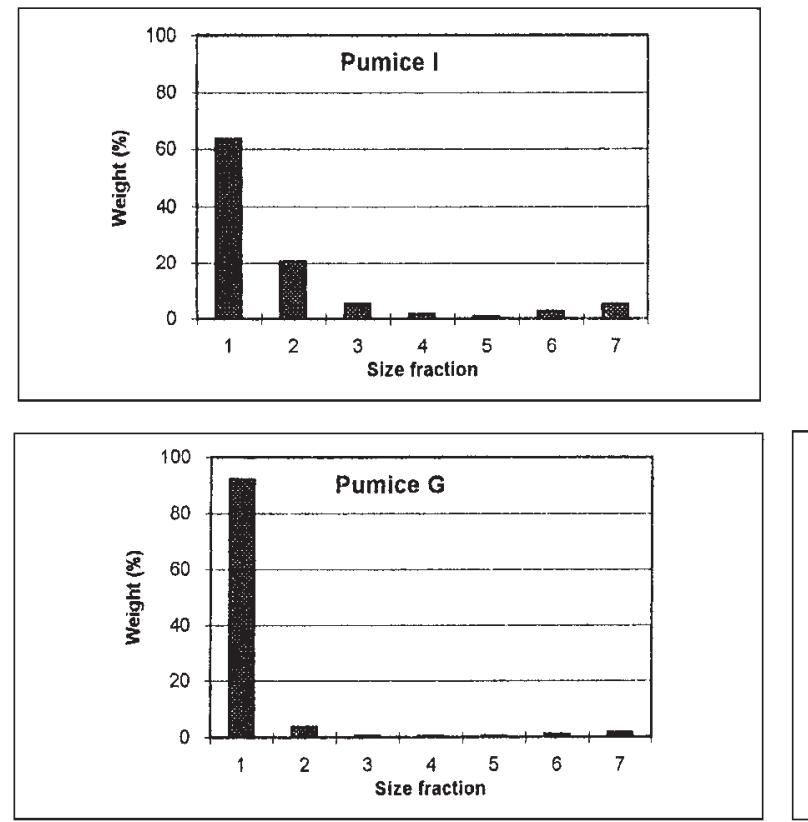

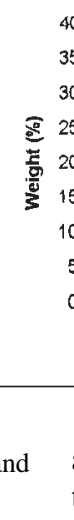

Fig. 1. Particle size distribution of the three media studied: [yellow tuff (YT) and pumice from Italy (PI) and Greece (PG)].

of YT, hold very little water at suctions that are considered useful $(10$ to $50 \mathrm{~cm}$ ) for container grown plants (Bunt, 1988). Most of the water is either drained out readily after irrigation (AFP) or held at suctions higher than $100 \mathrm{~cm}$, which are associated with very low unsaturated hydraulic conductivity (Wallach et al., 1992a, 1992b).

Hydraulic Properties. The measured retention curves and the nonlinear least-square fit of Eq. [1] for the retention curves of the media are presented in Fig. 2. The hydraulic model parameters are given in Table 3 . It should be noted that of the four parameters of the model, $\theta_{\mathrm{s}}$ was measured, whereas $\alpha, \mathrm{n}$ and $\theta_{\mathrm{r}}$ were calculated to fit the measured data. Good agreement between the measured and fitted retention data was obtained throughout the tested suction range. The predicted relative hydraulic conductivity vs. suction for the YT and pumice media is shown in Fig. 3. These curves were calculated by Eq. [2] with the parameters given in Table 2. As suction increased from 0 to $25 \mathrm{~cm}, \mathrm{~K}_{\mathrm{r}}(\mathrm{h})$ decreased by about three orders of magnitude for YT and by about six and eight orders of magnitude for PI and PG, respectively. The decrease in the predicted values of $\mathrm{K}_{\mathrm{r}}(\mathrm{h})$ as suction increased from 10 to $50 \mathrm{~cm}$, over the range of EAW, was about two orders of magnitude for YT and three orders of magnitude for PI; for PG an even a larger decrease is expected.

YIELDS. The cumulative yield and its quality in the three growing media are given in Table 4 for the main export season (October to April) and for the summer season (May to September). During both picking seasons, the yields (flowers/plant/week) were affected significantly by the growth media. Contrary to its effect on yield, the medium had no effect on flower quality, as expressed by average weight and by length (not shown) and percent marketable flowers (Table 4).

The differences in both total and relative productivity between the two picking periods are noteworthy. The higher irradiance levels in the May to September period results in much higher yields per week. The quality of these flowers is, however, somewhat lower than that of the October to April period, probably due to competition among simultaneously emerging buds (Raviv, 1986). The relative advantage of YT-grown plants over pumice-grown plants is higher in May to

\begin{tabular}{|c|c|}
\hline \multicolumn{2}{|c|}{ Particle size } \\
\hline$>4.75$ & 1 \\
\hline $1.70-4.75$ & 2 \\
\hline $0.85-1.70$ & 3 \\
\hline $0.36-0.85$ & 4 \\
\hline $0.25-0.36$ & 5 \\
\hline $0.10-0.25$ & 6 \\
\hline$<0.10$ & 7 \\
\hline
\end{tabular}

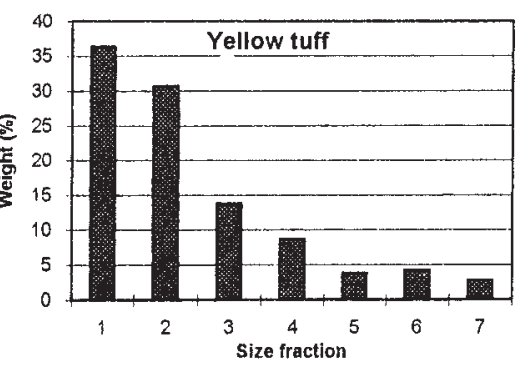

September than in October to April.

\section{Discussion}

As irrigation pulses were controlled by tensiometers, set at very low suction values, the difference in yields among the three mediacannotbe ascribed todeficiency in EAW, since suctions within the containers never reached the upper limit of this suction range $(50 \mathrm{~cm})$. It is suggested that the yield differences among media are attributable to the difference in hydraulic conductivity values within the suction ranges that existed in the different media, as will be discussed in the following. Examination of the hydraulic conductivities within the relevant suction ranges (Fig. 3) reveals a large

Table 2. Bulk density (BD), effective pore space (EPS), air-filled porosity (AFP), easily available water (EAW), and water buffering capacity (WBC) of the three media studied [yellow tuff and pumice from Italy (PI) and Greece (PG)].

\begin{tabular}{lccc}
\hline \hline Parameter & Yellow tuff & PI & PG \\
\hline BD $\left(\mathrm{g} \cdot \mathrm{cm}^{-3}\right)$ & 0.93 & 0.71 & 0.64 \\
EPS $(\%, \mathrm{v} / \mathrm{v})$ & 63.7 & 69.9 & 74.9 \\
AFP $(\%, \mathrm{v} / \mathrm{v})$ & 12.8 & 27.1 & 40.6 \\
EAW $(\%, \mathrm{v} / \mathrm{v})$ & 9.9 & 3.8 & 2.1 \\
WBC $(\%, \mathrm{v} / \mathrm{v})$ & 3.6 & 2.3 & 1.3 \\
\hline
\end{tabular}

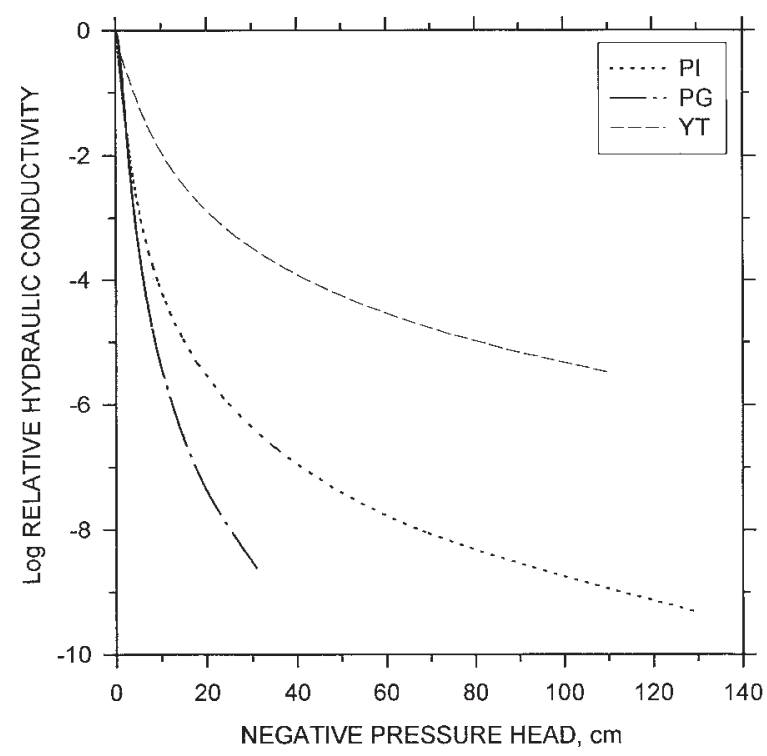

Fig. 2. The measured water retention values (OBS) and the nonlinear least-square fit (FIT) of Eq. [1] for the retention curves of the three media studied: [yellow tuff (YT) and pumice from Italy (PI) and Greece (PG)]. 
Table 3. Hydraulic model parameters: measured value of saturated moisture content, $\theta_{\mathrm{s}}$, and fitted values of residual water content, $\theta_{\mathrm{r}}$, and the parameters $\alpha$ and $\mathrm{n}$ of the three media studied [yellow tuff (YT) and pumice from Italy (PI) and Greece (PG)].

\begin{tabular}{lccccc}
\hline \hline Medium & $\begin{array}{c}\theta_{\mathrm{s}} \\
{\left[\mathrm{cm}^{3} \cdot \mathrm{cm}^{-3}\right]}\end{array}$ & $\begin{array}{c}\theta_{\mathrm{r}} \\
{\left[\mathrm{cm}^{3} \cdot \mathrm{cm}^{-3}\right]}\end{array}$ & $\begin{array}{c}\alpha \\
\left(\mathrm{kPa}^{-1}\right)\end{array}$ & $\mathrm{n}$ & $R^{2}$ \\
\hline YT & 0.64 & 0.33 & 0.178 & 1.647 & 0.9934 \\
PI & 0.70 & 0.38 & 0.594 & 2.052 & 0.9945 \\
PG & 0.75 & 0.32 & 0.589 & 2.813 & 0.9984 \\
\hline
\end{tabular}

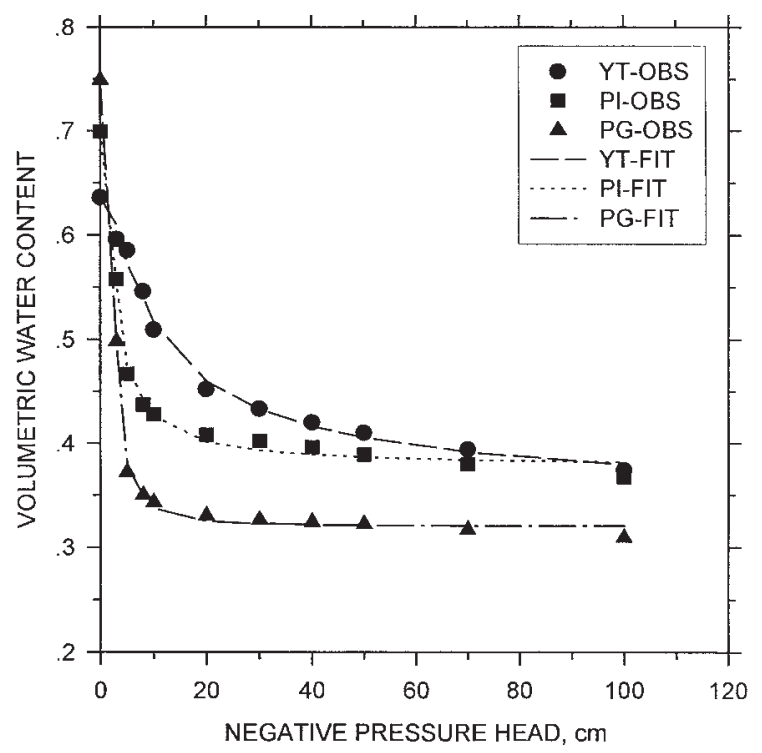

Fig. 3. Predicted relative hydraulic conductivities vs. water pressure head of the three media studied. The curves were calculated using Eq. [2] with the parameters given in Table 2 .

variation among the media: the relative hydraulic conductivity of tuff decreases by three orders of magnitude within the suction range $0<\mathrm{h}<20 \mathrm{~cm}$ whereas its decrease for PI is five orders of magnitude and for PG more than six orders of magnitude- - both within a suction range of $0<\mathrm{h}<15 \mathrm{~cm}$. Based on the physical properties of the of the media (Table 2) it is expected that differences in the saturated hydraulic conductivity, $\mathrm{K}_{\mathrm{s}}$, are minor compared to the differences in $\mathrm{K}$ for the relevant values of suction (Fig. 3 ). Thus, comparison between relative hydraulic conductivity of the given media can be related, for all practical purposes, to the absolute values of the hydraulic conductivity

The water flux from the media to the roots is linearly correlated with the actual hydraulic conductivity of the media and the suction difference between the roots and the media in their close vicinity. Between irrigation pulses, water uptake by the plant reduces the moisture content, increases the suction, and decreases the hydrau- lic conductivity at the root vicinity. At a given combination of aerial conditions, maintaining a constant water flux from the medium to the roots necessitates an increase of the suction at the root in order to compensate for the decrease in the medium's suction and hydraulic conductivity. From Figs. 2 and 3, it appears that the plant's ability to maintain a constant water uptake rate depended on its capability to adjust the root pressure to the decrease in the medium hydraulic conductivity. At periods of high transpirational demand, and without simultaneous water replenishment, rose plants grown in soilless media may exhibit reduced yield resulting from two different mechanisms, both reflected as increased frequency of flower bud abortion (blindness).

a) The plants respond to their inability to meet transpirational demand by closing the stomata, leading to reduced transpiration rate and restricted carbon exchange rate. Prolonged periods of high stomatal resistance can result in temporary deficiency in photosynthates availability to newly formed flowering shoots. Competition for carbohydrates among rose shoots is a welldocumented cause of 'blindness' (Bredmose, 1997; Zeroni and Gale, 1988).

b) In young, developing shoots, the mechanism of stomatal closure is not fully functional. The resultant decrease in turgor immediately arrests wall stretching, which in turn leads to the cessation of expansive growth of the flower bud and subsequently, to its abscission.

The role of hydraulic conductivity variation in yield, through its major effect on water flux from the medium to the root, is clearer when comparing yield variations among the media between the picking seasons. Yield differences between tuff and the pumices were greater in the summer than in the cooler period, in spite of the frequent irrigations, large amount of irrigation water and average low suction that was maintained in the containers. The unbalanced higher water fluxes due to increased radiation and vapor pressure deficit were more pronounced during the summer, although the same suction ranges were maintained in the two picking seasons. The summer's transpirational demand exceeded the maximum water flux that can flow from the pumice media to the roots within the relevant range of hydraulic conductivity, for longer periods than in the winter, accentuating the negative effects of low water availability.

The presented results suggest that unsaturated hydraulic conductivity indicates the actual availability of water to the roots better than the widely used concept of EAW, that is based on a predetermined suction range, independent of the hydraulic characteristics of the media. Unsaturated hydraulic conductivity - a very sensitive to moisture and suction characteristic function of a medium, in conjunction with climatic parameters, should be used for irrigation control of container-grown plants. As variations in hydraulic conductivity at the soil-root interface vicinity cannot be measured at present in situ, methods to optimize irrigation management practices need to be further investigated.

Table 4. Effect of various volcanic growth media [Yellow tuff (YT) and pumice from Italy (PI) and Greece (PG)] on yield parameters of cut 'Mercedes' roses: Average number of flowers per plant per week (FPW), average flower weight, and percent marketable flowers.

\begin{tabular}{|c|c|c|c|c|c|c|}
\hline \multirow[b]{2}{*}{ Medium } & \multicolumn{3}{|c|}{ Main season } & \multicolumn{3}{|c|}{ Summer season } \\
\hline & FPW & $\begin{array}{l}\text { Avg } \\
w t \\
(g)\end{array}$ & $\begin{array}{c}\text { Marketable } \\
\text { flowers } \\
(\%)\end{array}$ & FPW & $\begin{array}{l}\text { Avg } \\
w t \\
(g)\end{array}$ & $\begin{array}{c}\text { Marketable } \\
\text { flowers } \\
(\%)\end{array}$ \\
\hline$\overline{\mathrm{YT}}$ & $2.51 \mathrm{a}$ & $17.9 \mathrm{a}$ & $55 \mathrm{a}$ & $4.27 \mathrm{a}$ & $14.1 \mathrm{a}$ & $50 \mathrm{a}$ \\
\hline PI & $2.15 \mathrm{~b}$ & $18.3 \mathrm{a}$ & $55 \mathrm{a}$ & $2.92 \mathrm{~b}$ & $14.8 \mathrm{a}$ & $46 \mathrm{a}$ \\
\hline PG & $1.97 \mathrm{c}$ & $18.2 \mathrm{a}$ & $55 \mathrm{a}$ & $2.68 \mathrm{~b}$ & $14.4 \mathrm{a}$ & $45 \mathrm{a}$ \\
\hline
\end{tabular}

${ }^{\mathrm{z}}$ Within columns, figures followed by the same letter do not differ significantly at $P>0.05$. 


\section{Literature Cited}

Bredmose, N. 1997. Chronology of three physiological development phases of single-stemmed rose (Rosa hybrida L.) plants in response to increment in light quantum integral. Sci. Hort. 69:107-115.

Bunt, A.C. 1988. Media and mixes for container grown plants. Unwin Hayman, London.

da Silva, F.F., R. Wallach, and Y. Chen. 1993. A dynamic approach to irrigation scheduling in container media, p. 183-198. Proc. 6th Intl. Conf. Irr., Tel Aviv, Israel.

Gunnlaugsson, B. and S. Adalsteinsson. 1995. Pumice as environmentfriendly substrate-A comparison with rockwool. Acta Hort. 401:131136.

Mualem, Y. 1976. A new model for predicting the hydraulic conductivity of unsaturated porous media. Water Resources Res. 12:513-522.

Noland, D.A., L.A. Spomer, and D.J. Williams. 1992. Evaluation of pumice as a perlite substitute for container soil physical amendment. Commun. Soil Sci. Plant Anal. 23:1533-1547.

Raviv, M. 1986. Summer pruning of greenhouse-grown roses under subtropical conditions. HortScience 21:80-81.

Raviv, M. and Sh. Medina. 1997. Physical characteristics of separated cattle manure compost. Compost Sci. Utilization 5:44-47.

Raviv, M., Sh. Medina, Y. Shamir, and Z. Ben Ner. 1992. Very low medium moisture tension- $\mathrm{A}$ feasible criterion for irrigation control of container-grown plants. Acta Hort. 342:111-119.

Raviv, M., H. Nerson, Sh. Medina, R. Berdugo, Y. Shamir, A. Krasnovsky, and Ben Ner. 1993. Moisture tension of the growing medium and irrigation control of container-grown plants, p. 199-209. Proc. 6th Intl. Conf. Irr., Tel Aviv, Israel.

Silber, A., B. Bar-Yosef, A. Singer, and Y. Chen. 1994. Mineralogical and chemical composition of three tuffs from northern Israel. Geoderma 63:123-144.

Teres, V., A.I. Buenza, and A. Artexte. 1997. Substrate saturation by vacuum application. Acta Hort. 450:381-388.

Van Genuchten, M. Th. 1980. A closed-form equation for predicting the hydraulic conductivity of unsaturated soils. Soil Sci. Soc. Amer. J. 49:12-19.

Wallach, R., F.F. da Silva, and Y. Chen. 1992a. Unsaturated hydraulic characteristics of composted agricultural wastes, tuff and mixtures. Soil Sci. 153:434-441.

Wallach, R., F.F. da Silva, and Y. Chen. 1992b. Unsaturated hydraulic characteristics of tuff (scoria) from Israel. J. Amer. Soc. Hort. Sci. 117:415-421.

Zeroni, M. and J. Gale. 1988. Response of Sonia roses to continuous daytime $\mathrm{CO}_{2}$ supplementation under controlled environment conditions. Austral. J. Agr. Res. 39:863-870. 